\title{
Evaluating the Competition Environment between the Global Chain Quick Service Restaurants and the Local Egyptian Quick Service Restaurants in Egypt Mohamed Abdelgawwad Aly Abdelgawwad \\ The University of Sadat City, Egypt
}

\begin{abstract}
The world became global village as a result of the globalization in these days. So, the global Quick Service Restaurants (QSRs) expanded globally especially in the Arab markets. The global QSRs adapted local traditional products from the host countries to compete with the local Egyptian QSRs. The main purpose of this paper is to evaluate the comparative case study of globalizing the local products which served by McDonald's QSRs versus, localizing the global products served by local Egyptian chain QSRs which offers some useful lessons for global QSRs entering Arab markets.

This research will explore the importance of adapting marketing mix for global QSRs in the Arab markets through a case study of McDonald's McFalafel and McArabia sandwich in Egypt. On the other side, the local Egyptian QSRs adopting the same strategies to penetrate the global QSRs' market share such as; localizing the global products (with little modifications), variety of products; standards of cooking; serving; location; training; equipment; decoration and so on. The local Egyptian chain QSRs all the time compete the global chain QSRs to attract large numbers of the global QSRs' customers.

Keywords: Globalization, Global QSRs, Local Egyptian QSRs, Competition, Glocal product.

\section{Introduction}

The main aim of this paper is to evaluate the comparative case study of globalizing the local products (Mcfalafel and Mcarabia sandwiches) which served by McDonald's QSRs and localizing the global products (Burger Yaar and burger Zaad) that served by Mo'men local chain QSRs which offers some useful lessons for global QSRs entering Arab markets. This research will explore the importance of adapting marketing mix for global company in the Arab markets through a case study of McDonald's McFalafel and McArabia sandwich. On the other side, the local Egyptian QSRs adopting the same strategies of the global QSRs to penetrate the global QSRs' market share such as localizing the global products (with little modifications), variety of products; standards of cooking; serving; location; training; equipment; decoration and so on. The local Egyptian chain QSRs all the time compete the global chain QSRs to attract a large number of the global QSRs' customers.

There is a continuous change in the customers' needs depends on the new trends in local markets which affected by the global markets. On one hand, the global QSRs try always to launch new products to suit local customers taste with achieving profit in the hosting countries by adapting and modified products. On the other hand, the local Egyptian QSRs localize the global products to survive which launched to sustain and maintain its brand name.
\end{abstract}

\section{Literature review}

Huge technological advances in transportation and communications, have turned the world into one geographical entity (Vignali, 2001), a single market (Pizam, 2010), a global and small village. This has resulted in a series of unexpected changes, including the integration of national economies into a global economy through foreign direct investment, capital flows, migration and spread of technology (Bogicevic et al., 2008). Accordingly, globalisation stretches the borders of 
the world's market to include more places in the supply of new and different types of consumer goods and thus global brands have become more available to local customers (Sun \& Chen, nd). Globally branding has a number of advantages including: cost efficiencies; the sharing of resources; the ability to attract partners, employees and customers to enter new markets (Pizam, 2010). However, there are also a number of disadvantages, such as not meeting the needs of specific markets and local taste preferences (Gagliardi, 2001; Czinkota \& Ronkainen, 2007).

The global brands are a key part of the globalisation process which is driven by standardization. Thinking globally whilst acting locally is a critical issue for global brands to ensure that they can respond to the specific needs of local markets. The extent to which franchisees can act locally and launch new adapted products if they are required to get permission from the parent company is a potential obstacle for franchisees. Local cultures, language differences, government regulations and political issues pose significant challenges for global brands (Gregory \& Wiechmann, 2002).

On the other side, localisation involves the development of marketing strategies for a specific region according to its cultural, regional and national uniqueness. "Localized strategies or localization ... involves marketing strategies for a specific region according to its cultural, regional and national uniqueness" Prakash \& Singh (2011:2). There are a number of push factors for localization including cultural factors (habits and traditions), commercial factors, legal factors and technical factors (Lasserre, 2007). However, some multinational enterprises apply hybrid strategies, commonly referred to as "glocalisation", which combine globalization and localization to emphasize that a global product will succeed when it is adapted specifically to meet the needs of that region (Kumar \& Goel, 2007).

There is no doubt that taking account of local taste preferences is the key to success for global QSRs which aim to operate across international borders to maintain its success. These companies should consider the importance of taste preference before they produce menu items outside their home country. Taste preferences are influenced by culture (Wright et al., 2001) as:

People in different cultures have certain dietary preferences so some foods are preferred in one culture may be avoided in another, such as the Hindus in India regard the cow as a sacred animal therefore, Hindus don't eat beef, which is the main type of meat for hamburger in the United States and many other countries.

To fully understand the culture of a society from a food perspective it is important to understand the taste preferences of consumers from that culture (Wright et al., 2001). "Taste is one of the most important individual influences on food choice is taste, which also is influenced by the aroma and texture of food" (McGinnis et al., 2006: 95). The geographical, historical and economic aspects of a culture all shape the taste preferences of consumers (Wright et al., 2001). As a result of cultural diversification, McDonalds has developed products in different countries to reflect national traditional dishes and so suit local tastes (Molz, 2006). Restaurants are an important part of the hospitality industry and a significant part of modern-day life. As suggested by Liu \& "Restaurants are part of an industry system providing services to people away from home that becomes progressively more general and broader as it moves from restaurants to food service to hospitality industry." Chen (2000: 122).

Ball \& Roberts (2003: 31) define a restaurant as "an establishment where refreshments or meals can be obtained, usually for money by the public". However, there are many diverse operations which would be included in this definition, for example pubs (especially gastropubs), bistros, snack bars, cafés, specialty restaurants (such as WokToWalk in the UK), popular restaurants and some fish and chip cafés (Jones, 2002). QSRs may also be 'drive through' operations in which 
payment windows are sometimes separate from food pick up windows to save time (Baraban \& Durocher, 2010). The key to success of the QSR business concept centers on reducing production costs through reducing labor and other costs whilst delivering consistent product quality quickly to customers. As Ottenbacher \& Harrington (2009: 525) said: "The food innovation process focuses on consistency of product quality with the key to success being able to deliver the order quickly to customers to eliminate labour and equipment costs in the individual stores".

QSRs originated in the United States of America (USA) - Americans often live in a hurry and enjoy fast food, i.e. food on the run (Walker, 2008). History tells us that the first-known QSR dates back to the 1870s, when a New York City food service operation - The Plate House served a quick lunch in about ten minutes. Today many QSRs precook or partially cook food so that it can be finished off quickly - 'it is seconds that count in QSR operations' (Walker, 2008: 27). "QSRs operations are now more global than ever and international fast food eating continues to increase in popularity" (Kara et al., 1995: 318). The QSR industry is one of the most competitive and saturated business sectors in the USA (Apte \& Reynolds, 1995) and "Some of the most successful and largest restaurant chains are part of the quick-service restaurants (QSRs) segment, such as McDonald's, Pizza Hut, Subway and KFC" (Ottenbacher \& Harrington, 2009: 524).

QSRs are mass production units which offer consistent quality of service (Apte and Reynolds, 1997): QSR food is highly processed and prepared on a large scale with standardized cooking and production methods, in the most cases menu items are made from processed ingredients prepared at central supply facilities (or prepared by suppliers) and then transported to individual outlets where the food is reheated and cooked in a short amount of time.

(Ottenbacher \& Harrington, 2009: 525)

Today's hectic lifestyles and the demand for convenience products are leading to an increased demand for QSR products (Hahm and Khan, 2001). Although most QSRs provide cheap and less-than-nutritious meals they do offer quick, consistent quality meals at affordable prices which attracts customers, particularly young customers and families (Klessig, 2009).

In recent years, the global development and growth of QSRs has become a significant phenomenon as exemplified by the world-wide explosion of McDonald's, KFC and Pizza Hut outlets (Ball \& Roberts, 2003). Franklin (2005) goes further in explaining the principles of QSRs, i.e. effectiveness, calculability, expectedness and control. He emphasised that quantity and standardisation replace quality and diversity as indicators of value and serve as a symbol of the QSR preoccupation with efficiency. The QSR industry survives on the rigid principle of delivering cheap food of consistent quality at high speed (Blacharski, 2006). These principles were first pioneered by McDonald's: QSC (Quality, Service and Cleanliness) (Reiter, 1996) - the style of service based on low cost and standardized products has contributed to the popularity of QSRs (Kovacik, 1998).

Ball \& Roberts (2003) explained that independent restaurants are owned and managed by individuals. In contrast to chain restaurants, independent restaurants have the significant advantage of having the freedom to "do their own thing" in terms of concept development, menus, décor and to change or add items (Walker, 2008:21). In case of smaller, independent restaurants much relies on the knowledge and the dedication of the hired managers (Alonzo, 2007). Small businesses often have more friendly approach than chain operations (Hiller, 2003) and they also can occupy special niche markets catering for the needs of particular customers. 
Chain restaurants are restaurants that are a part of a multi-unit organisation.

They often share the same menu, purchase supplies and equipment cooperatively, and they follow operating procedures that have been standardised for every restaurant in the chain.

(Gordon-Davis \& Densburg, 2004: 269)

QSR chains have several advantages over independent QSRs, such as: their branding and associated reputation in the marketplace; greater advertising influence; sophisticated systems development; cheap purchasing, access to capital, buying power and the ability to benefit from economies of scale and offer lower prices (Hiller, 2003; Walker, 2008). However, one significant disadvantage is that there is often a lack of a friendly approach to customers. The future of small independent QSRs will be more secure if they play to their strengths and exploit the weaknesses affecting the chain QSRs (Boer,1992). Ball \& Roberts (2003) compared the competitive advantages and disadvantages of independent and chain QSRs (see Table 1).

Table 1: Competitive advantages and disadvantages of independent and chain QSRs

\begin{tabular}{|c|c|c|}
\hline QSRs & Competitive advantages & Competitive disadvantages \\
\hline Independent & $\begin{array}{l}\text { Flexible } \\
\text { Specialising offers } \\
\text { Direct control strategy } \\
\text { Image, consistency } \\
\text { independence } \\
\text { Entrepreneurial drive } \\
\text { Close to customers }\end{array}$ & $\begin{array}{l}\text { Limited bargaining power } \\
\text { Few economics of scale } \\
\text { Reduce media access } \\
\text { Over-dependence on owner } \\
\text { Limited planning } \\
\text { Inertia } \\
\text { Often lack of specialist retail } \\
\text { Expertise and capital to expand } \\
\text { Offer greatest risk }\end{array}$ \\
\hline Chain & $\begin{array}{l}\text { Bargaining power } \\
\text { Multiunit efficiencies } \\
\text { Great use of sophisticated } \\
\text { technologies } \\
\text { Well-defined management } \\
\text { Capital } \\
\text { Often able to attract expansion } \\
\text { Specialist expertise } \\
\text { Long-range planning }\end{array}$ & $\begin{array}{l}\text { Inflexibility } \\
\text { High investment costs } \\
\text { Reduced managerial control } \\
\text { Limited independence }\end{array}$ \\
\hline
\end{tabular}

Source: Ball \& Roberts, 2003 cited in Abdelgawwad, 2012.

Competition is a significant issue in the QSR market and affects both global QSRs and local QSRs. In the Egyptian QSR market, national brands (like Mo'men, Wessaya and Cook Door) are small but significant competitors to global QSR brands (e.g. McDonald's, Burger King, and Wendy's) (Reid and Bojanic, 2010). Moreover, it is not just competition from other QSRs, there is also indirect competition:

Today's QSR are not only competing with other QSR but also with many quick casual and casual dining restaurants such as Baja fresh, Chili's and outback, furthermore QSR competing with the increasingly present "Ready-to-eat" meals available in most grocery stores.

(Ottenbacher \& Harrington, 2009: 525)

The appropriateness of the product to the market is a critical success factor for QSRs: 
The success of new products depends on the product's fit with the firm 's strength and a defined market opportunity. Market characteristics and competitive situation will also affect the sales potential of new products.

(Ferrell\& Hartline, 2011:198)

The foodservice industry has become highly competitive as the number of foodservice outlets has increased to meet the demand. In order to succeed in such a competitive industry, restaurant operators need to understand the factors (and their relative importance) that influence restaurant patrons' decision when selecting a restaurant.

(Sriwongrat, 2008: 2)

This strong competition has happened because: "The ongoing globalization of markets and increased competition worldwide has made international marketing decisions ever more important to survival, growth and profitability of international corporations (MNCs)" (Katsikeas et al., 2006: 867).

Quick-service restaurant (QSR) chains are among the many types of restaurants that are interested in building strong brands, but achieving that goal is not always easy. Given that many QSR chains' products and services are not inherently differentiated and the channels of distribution are not distinctive, customers often have only price and brand equity to differentiate one brand from its competitors. In the absence of strong brands, the only remaining ongoing marketing mechanism is price manipulation, usually in the form of discounting. Indeed, the QSR industry has heavily relied on price promotions as an important marketing activity. That emphasis has resulted in continual price wars that have damaged customer loyalty and reduced revenue.

(Kim \& Kim, 2004: 116)

Operators should take competition into consideration at all times (Cebrzynski, 2008). In the face of strong competition, global and local QSRs try to launch new products to maintain their image and to attract customers:

Global competition, rapidly changing technologies, reduced product life cycles; cost reduction, high quality products and more demanding end customers are some of the factors that have made companies to look for new strategies for developing new products. New product development process includes all the activities from the development of an idea or a concept for a product, to the realization of the product during the production stage and its introduction into the market place.

(Verdecho et al., 2009)

It is vital for global QSRs to consider the political and legal environment by understanding rules and regulations in the host country; this will be at all levels of government (local, state, national and international) to gain a competitive edge (Reid and Bojanic, 2010). "Competition is defined as direct and indirect ways customers can satisfy needs a part from making an exchange for a particular offering" (Sandhusen, 2008: 6). Companies have to be ever-vigilant because they do not know where the competition will come from next.

McDonald's spokeswoman Ashlee Yingling said that "the attention from our competitor is flattering. Our attention continues to be providing customers food they have come to love, value and convenience only McDonald's can provide.

(Hulghlett, 2009: online) 
"The fast-paced, highly-competitive nature of quick service restaurants (QSRs) has motivated members of the industry to develop creative ways to optimize customer satisfaction" (Gregory et al., 1998: 21). "Use the ocean as a metaphor to describe the competitive space in which an organization chooses to swim (Kim and Mauborgan, 2005 cited in Hollensen, 2007: 115). Competition in the QSR marketplace is very strong and the term "red ocean competition" refers to the real competition in Egyptian QSRs market:

Red oceans refer to the frequently accessed market spaces where the products are well-defined, competitors are known and competition is based on price, product quality and service. In other words, red oceans are an old paradigm that represents all the industries in existence today.

(Hollensen, 2007: 115)

There is also blue ocean competition which is very different to the competition in the Egyptian QSR market:

Blue oceans denote an environment where products are not yet well-defined, competitors are not structured and the market is relatively unknown. Companies that sail on the blue oceans are those beating the competition by focusing on developing compelling value innovations that create uncontested marketplace. Adaptors of blue ocean strategy believe that it is no longer valid of companies to engage in head-to-head competition in search of sustained, profitable growth.

(Hollensen, 2007: 115)

Reid and Bojanic (2010) identify an adapted version of the imitative strategy where firms respond to a competitor's new product in which the firm's primary goal is to improve on the initial product. This strategy is heavily relied on in the QSR industry. Every time McDonald's launches a successful new product:

The proximity of one fast food restaurant to others may have an effect on its success. If another establishment that serves identical meals is within a close range, the result will be increased competition and potentially lower gross sales. A restaurant that is near a similar one must attempt to draw customers from the competition with promises of additional benefits, features and lower prices. Obviously the highest chances of success exist when there are no other fast food restaurants close by.

(Gambone, nd)

Global QSR companies must consider the alternative products which are available to the customer in the marketplace. This is a very important issue in relation to the success and failure factors which impact on new products. For example, the failure of McDonald's McFalafel sandwich shows that there were many substitute products in the Egyptian market and moreover, that these substitute products were lower in price. At the same time, there were no substitute products for the McArabia sandwich available in the Egyptian market. Furthermore, the original dish for McArabia - kofta - is an expensive product:

When an alternative product hits the market, the competition between the existing product and the new one can cause the demand to drop. Just as many people may be buying the product, a large portion of them may elect to buy the alternative brand. This leads to price wars that ultimately lower the price of the product and may require a cut in supply to fall in line with the decrease in demand.

(Morgan, 2011: online) 


\section{Methodology}

All the data obtained in this research was collected in sixty semi-structured interviews with industrial practitioners and experts in Egypt in 2016. This fieldwork contains from twenty-five semi-structured interviews with local QSRs and on the other hand, thirty-five interviews with managers and practitioners in the global QSRs. The interviews were designed to draw on the perceptions and experiences of the marketing which impact competition on the operation of global and local chain QSRs. The global chain QSRs take action as drivers for the development of new glocal products (local style with authentic taste in the global uniform). On the other side, the local Egyptian chain developed it's the local Egyptian products by localizing the global products in the Egyptian uniform (global style with authentic taste) to meet the local Egyptian taste and preference.

The global chain QSRs participating in the study were McDonald's, Hardee's, Kentucky Fried Chicken (KFC) and Burger King QSRs. The local Egyptian chain QSRs competing with the global chain QSRs in the Egyptian market that participated in the study were Mo'men, Cook Door and Wessay QSRs. The research adopted a comparative case study between two McDonald's products to give in depth exploration factors which lead to continue new product in the Arab markets countries market. A research strategy comprises an all-surrounding method cover the sense of design, data gathering techniques, and specific approaches to data analysis according to (Yin 2003).

The methodology this research evolved a comparative case study (Yin, 2009) between the glocal products (the McFalfel and McArabia sandwiches) which served by the global chain QSRs in McDonald's Egypt. On the other hand, the process of localizing global products is served by Mo'men as one of the local Egyptian chain QSRs. The two comparative case studies are planned in this research, the first is McFalafel and McArabia sandwiches with knowing the real reasons for competing between the global QSRs and local Chain QSRs in the Egyptian QSRs market. This stiffness competition leads to launch new generation of sandwich in both of global and local QSRs in the Egyptian market. The semi-structured interviews permitted for detailed probing of respondents' views and opinions and facilitated the explanation of answer when essential. These semi-structured interviews discovered practical and theoretical viewpoints on the global QSR market in Egypt. I selected McDonald's Egypt for pragmatic reason. Furthermore, this research will go in depth to know the factors which make adapting is success or failure through cross two case studies analysis to represents recommendation for successful adapting for global QSRs in Arab countries.

Table 2: Abbreviations of interviewees

\begin{tabular}{|l|l|}
\hline Respondents & \multicolumn{1}{|c|}{ Position } \\
\hline IN.EX. & Industry Expert \\
\hline GC-QSRM1 & General manager \\
\hline GC-QSRM2 & Assist. Manager \\
\hline GC-QSRM3 & General marketing manager \\
\hline GC-QSRM4 & Training manager \\
\hline GC-QSRM7 & McD Branch manager \\
\hline GC-QSRB5 & Burger King branch manager \\
\hline LEC-QSRM1 & General manager \\
\hline LEC-QSRM3 & General marketing manager \\
\hline
\end{tabular}

\section{Results and Discussion}

According to the (IN.EX.) stated that globalisation plays an important part in increased competition in the QSR market: "the global is now like small village because of the 
globalization so any market in any country is open to any business. Day after day competition increases". The (GC-QSRM3) explained that: "there is a stiff competition (Red Ocean Strategy) in the Egyptian QSR market between global and local chain QSRs". Moreover, (GC-QSRM2) said that "The chains - KFC, Pizza Hut, Hardee's, Burger King - I believe you can consider these our main competitors. But we keep an eye on everyone, even the local chains like Mo'men, Cook Door and whatever - we keep an eye on them too". Sriwongrat (2008) and Reid and Bojanic (2010) also highlighted competition between the global chain QSRs like KFC, Pizza Hut, Hardee's and local chain QSRs as an issue in relation to the attraction and satisfaction of customers.

GC-QSRM3 explained: “... McDonald's competes not only with the other global and local QSRs but also with other restaurants like casual restaurants". Sandhusen (2000), Gregory et al. (1998) and Ottenbacher and Harrington (2009) similarly noted on the direct and indirect competition experienced by QSRs which not only compete with each other but also with casual dining restaurants and grocery stores which offer a range of ready-to-eat meals.

GC-QSRM3 explained: "Each QSR has different competitive advantages and must keep its identity through its standardised products for customers". The importance of identity was emphasised by one of the (GC-QSRM7): “... for example, Hardee's serve grilled hamburger sandwiches which are a unique product for Egyptians".

IN.EX. explained: "You must always keep your eye on your competitors. Competition is the subject of market research. Global QSRs should update themselves to compete and stay strong in the market. As, one of (GC-QSRB5) explained: "I visit my competitors to observe the positive and negative points in their restaurants". GC-QSRM4 explained the importance of pioneering: "It is not necessary to imitate your competitors after they have produced new products but you should be the first to market".

Stiff competition encourages each QSR chain to try to steal customers from their competitors. The (LEC-QSRM1) and (LEC-QSRM3) both explained that the location and décor of the restaurant, the service and the variety of the products were all tools that could be used to lure customers from the competition.

GC-QSRB5 identified two types of competition: “... red ocean ... and blue ocean. Red ocean refers to all competitors fighting with each other on the basis of price, quality, quantity, service, value for money to attract customers. Blue Ocean is about my restaurant being unique so there is no need to compete with others". The terms red ocean and blue ocean reflect those used by Kim and Mauborgan (2005) and Hollensen (2007). An example of red ocean competition between local and global QSRs in Egypt in which the Mo'men chain produced a leaflet sending a clear message to global QSR customers, especially McDonald's customers, about their unhealthy, 'plastic' sandwiches. The Arabic on the photograph translates as: "We do not eat plastic sandwiches. Mo'men QSRs serve real food".

As a result of the culture diversification, McDonalds has adapted some products of national traditions to suit with local taste in a global dress (Molz, 2006). Jakle and Sculle (1999) said that McDonald's has become not just an industry dominant, but a kind of cultural icon for much of what America has become, the introduction of the McDonald's chain into a new country (over 100 now) is taken as a sign on spreading American influence worldwide. "Consumer product companies such as Coca-Cola, and McDonald's have standardised production and distribution but still may customised their products to local tastes" (Gregory and Wiechmann, 2002: 14). Also, the menu of McDonald's has been tailored to suit local tastes and preferences by selected the most popular two dishes in Egypt which are Falafel and Kofta. For example, in France the 
menu is written in three to five different languages usually French, German, Italian, Belgian and Japanese. Some menus offered items in France are not available in the UK (Mok, 2001).

The competitive environment that can effect on a restaurant's success or failure through launching new generation of products and services to attract new customers in new markets, its speed of growth strategies, how to differentiate itself from other competitors also lack of experience in adaptation to foreign environmental conditions in the QSR market (Parsa et al., 2005). According to Porter (1979: 131) "Awareness of these forces can help a company stake out a position in its industry that is less vulnerable be attack." There are five basic forces the threat of new achievement; the threat of substitute products and services; bargaining power of customers; bargaining power of suppliers; intensity of competitive rivalry.

This sandwich launched to increase penetration to McDonald's by attracting a new segment of the Egyptian customers. In the first time of launching McFalafel (Elmaalim) sandwich was very successful in the beginning of launching which McDonald's sold one million sandwiches in the first two weeks of launching this sandwich but was not unbeaten sandwich in the Egyptian market: "McDonald's introduced the McFalafel sandwich which was very successful because McDonald's sold around a million sandwiches in just a matter of 10 to 14 days" (GC-QSRM1). "Mcfalafel (Elmaalim) sandwich is very successful because this sandwich makes a wide penetration. There are a huge number of new customers entered McDonald's restaurants for 3 months. (GC-QSRM3) "McDonald's restaurants served this sandwich as a fourth flavour". (GC-QSRM4) "This sandwich introduce as a fourth flavor; ordered for season; temporary item in menu" (GCQSRM3).

As mentioned above, that main reason for launching a new generation of products (Glocal product) is to increase C, D and E customers' class penetration in the Egyptian QSRs market as evident below: "McDonald's launched this local sandwich: to send a message for local customers: "I am local and I am a deep local" "I am Egyptian" to penetrate a segment which is not mine." To avoid the boycott which happened in those days (GC-QSRM2).

To decrease the impact of anti-American campaign McDonald's done product innovation by adapting Egyptian falafel sandwich as a new product called McFalafel (Elmaalim) sandwich. As commented by one of global QSRs branch manager: "We introduced a new sandwich called McFalafel (Elmaalim) to increase our sales" (GC-QSRM7) (GC-QSRM3) (GC-QSRM4).

There is another reason for this sandwich as evident below:" The factors that push McDonald have to introduce a new generation of sandwiches; customers' tastes; some kind of researches; we taste the products" (GC-QSRM3). Meanwhile, there is another point of view that a mother company made a global decision for all McDonald's branches all over the world to adapt local dishes from different cultures "McDonald's mother company made a global decision to all branches around the world to adapt different dishes from different local cultures"(GCQSRM4)(GC-QSRM7).

As I mentioned in the previous paragraph that this sandwich achieved wide range of sales in short time. This sandwich sale was high because all customers' segments were coming just for try Egyptian traditional sandwich which launched in American style, as evident below:

In the first time of launching Mcfalafel (Elmaalim) sandwich in the Egyptian market. It sold for a wide range of people because: it is very strange for McDonald's to adapt local Egyptian product and launched in American style. People are coming just to try to eat sandwich. All classes $A, B, C, D$, and $E$ eat this sandwich just once to try (GC-QSR4). 
Young people ordered this sandwich just for sitting with friends because this sandwich in those days is the cheapest item in McDonald's menu. In the same time, it is the best quality sandwich in Egypt in those days. But I did not intend to go with my friends to eat it because in comparisons with prices of this sandwich in local restaurants was expensive "The main objective from going to McDonald's are firstly to sitting out with my friends, Secondly if you would like to eat high quality falafel sandwich go to McDonald's because it is the best hygienic sandwich in Egypt" Gc-QSRM1.

Figure 1: The McDonald's globalized the local product.

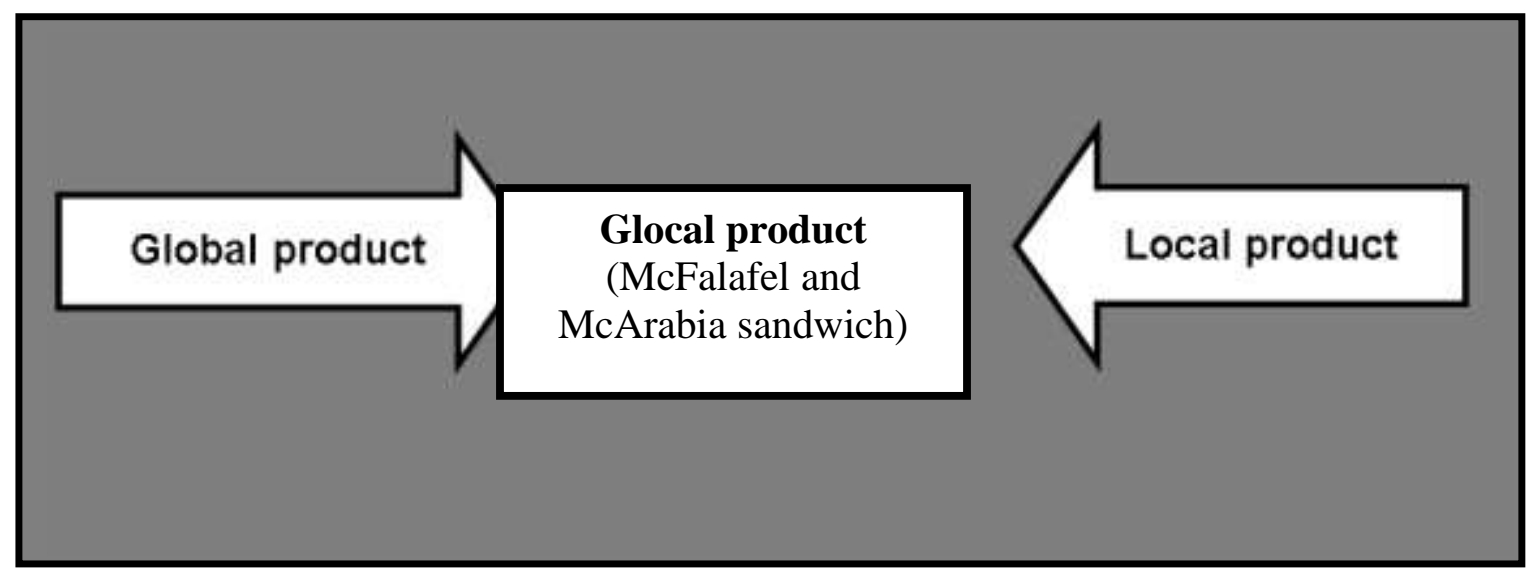

On the other hand, one of the local QSRs Mo'men compete with the global QSRs such as McDonald's by launching the global sandwiches with local dressing vis verse what McDonald's launching. One of the industry experts explained that "Mo'men launched new generation of sandwich such as Burger Yaar and Burger Zaad which are copy and paste from McArabia which served in McDonald's".

One of the LEC-QSRM1 explained that "the owner of Mo'men try to focus on new generation of products which served by the global QSRs to compete with them in the same category of products such as consistent quality, design and packaging". One the same vein, the local Egyptian QSRs as one of the branch managers expressed that "the local Egyptian QSRs served the all sandwiches in big size which is preferable for the Egyptian customers; otherwise, the global QSRs cannot compete with local Egyptian QSRs in the value for money which is a competitive advantage for the local QSR".

One of the (GC-QSRM7) explained that QSRs compete on six key aspects: "both of global and local QSRs compete with each other on effectiveness, cleanliness, quality, calculability, expectedness and control". Gregory et al. (1998) stressed that speed of service was a main feature of competitive advantage in both global and local Egyptian QSRs. As(GC-QSRM7) added: "We provide an exceptional service for our regular customers and greet them on first name terms. We also take special care of children because children encourage their families to eat in our restaurants". The (IN.EX.) underlined the importance of building the loyalty of children for McDonald's since the children of today re the parents of tomorrow: "McDonald's is a clever educator for its children". Hosting birthday parties is one tool for promoting loyalty amongst children. 
Figure 2: The Mo'men localized the global product

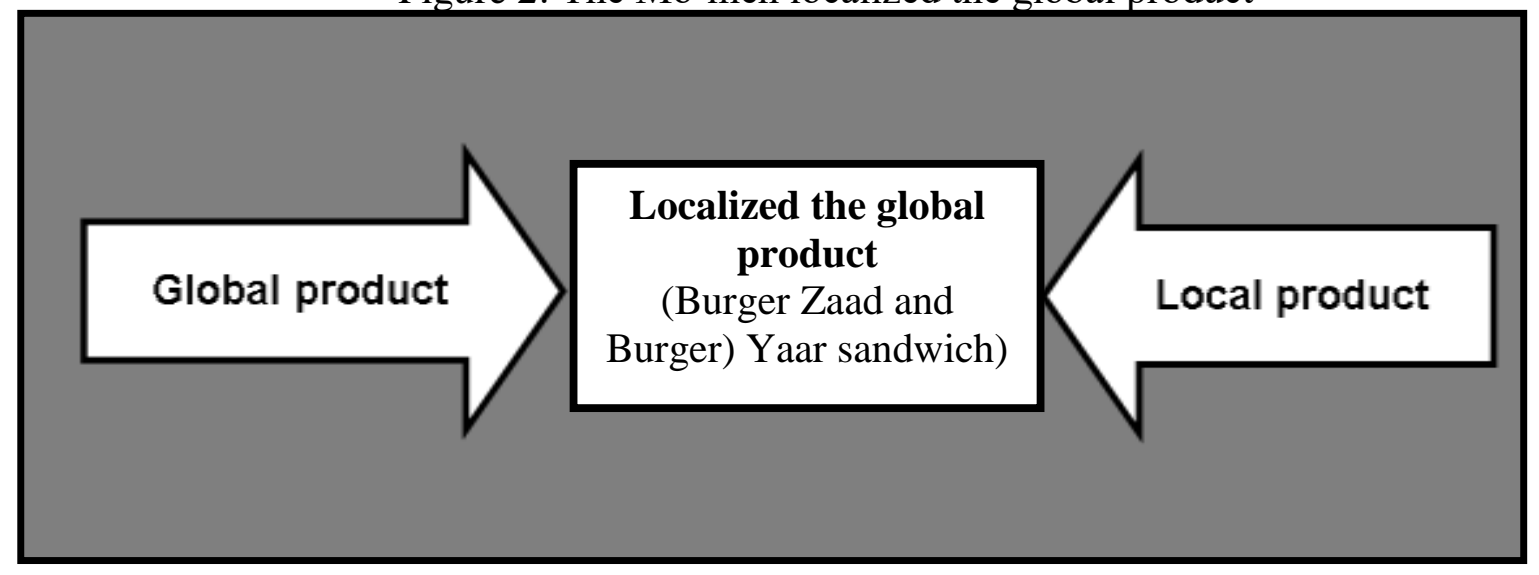

There is a stiff competition among the global and local Egyptian QSRs so one of the marketing managers of the global QSRs explained that "we are in the Global QSRS adapted and customized the local dishes in the global characteristics and standards such McArabia, Mc Kofta and Mcfalafel called the glocal products which adapted from the Egyptian traditional culture". Moreover, the global QSRs changed the package of these adapting dished which is totally different from others global products which served in McDonald's. Although McDonald's have produced a number of localized products the McFalafel sandwich was unusual in that it did not continue. McDonald's launched this sandwich as a part of its tactics in Egypt.

Figure 3: The competition process between the global Chain and local Egyptian QSRs

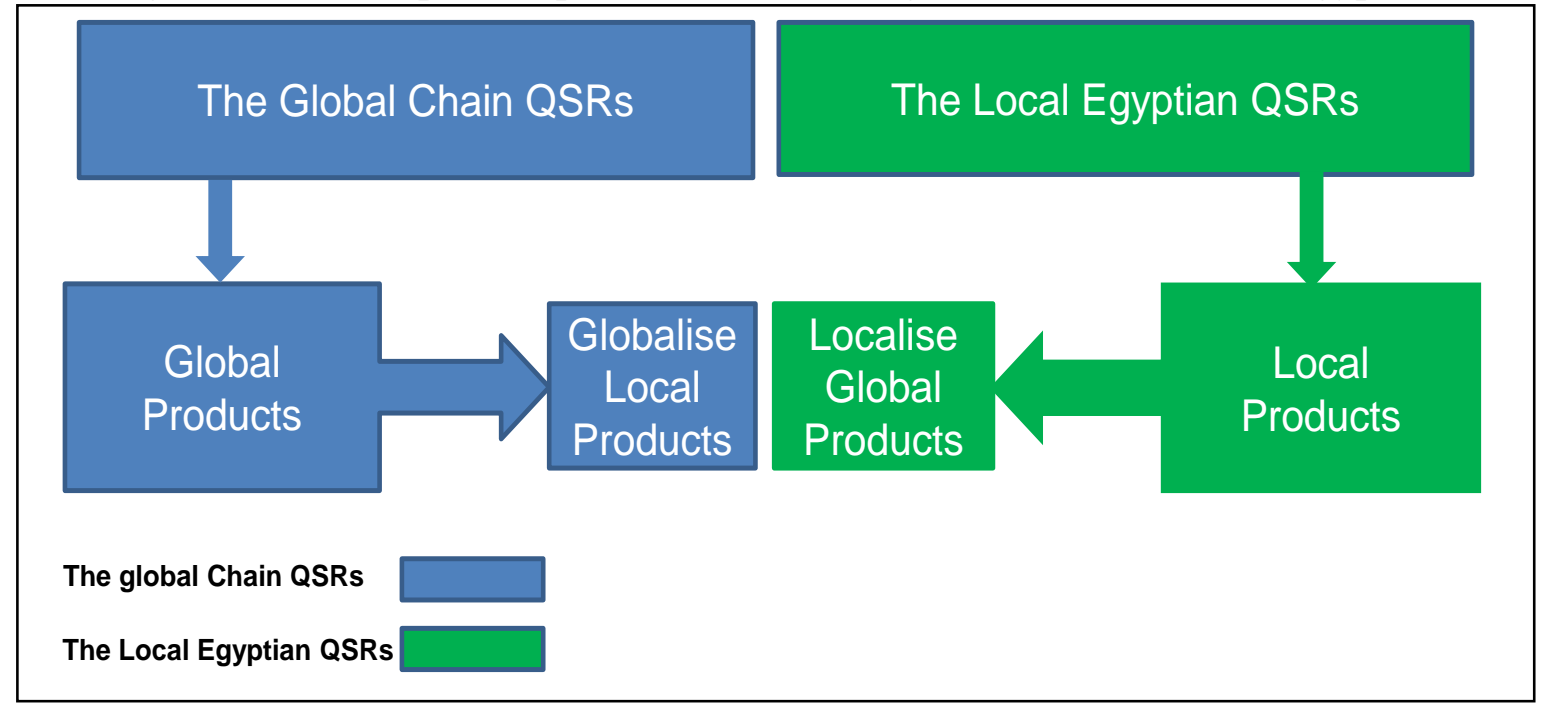

\section{Conclusion and Recommendations}

All in all, this article highlighted the competitive situation among the global chain QSRs and local Egyptian QSRs. There is a stiff competition among the global and local QSRs in everything: launching new products; type of service; time of serving; type of kitchen; type of cooking; configuration; production process and so on. Here this article highlight on the competition on launching new products by localizing the global products and globalizing the local products. This research recommended that:

- Red competition is a strong topic for study in the Egyptian QSRs market. 
- Local QSRs should consider new trends of global QSRs' products to satisfy the local Egyptian customers taste.

- Time is very important in launching new products so the local Egyptian QSRs should follow this rule which is "before time is on time, on time is late and late is not acceptable" (TGI Friday's concept)

- Global and local QSRs should: "Deliver what are you promise to their customers".

- The local QSRs should always keep its eye on competitors (global QSRs).

- The local QSRs should observe the positive and negative points in its restaurants.

- The local QSRs should avoid the rude advertising like "we do not plastic sandwiches".

- It is not necessary to imitate your competitors after they have produced new products but you should be the first to market.

- The local QSRs should update its products to satisfy the local customers' needs.

- The local QSRs should update itself to survive and sustain its brand name.

- The local QSRs should serve a variety of products in its menus.

- The importance of identity for every QSRs.

\section{References}

Abdelgawwad, M. A. A. 2012. Quality Management: Success and Failure Factors for New Glocal Product Development in Global Quick Service Restaurants: A case Study of McDonald's Egypt. Thesis. Wales. UK.

Alonzo, R. S. 2007. The upstart guide to owning and managing a restaurant. Kaplan Publishing.USA.

Apte, U. M., \& Reynolds, C. C. 1995. Quality management at Kentucky fried chicken. Interfaces: 6-21.

Ball, S. \& Roberts, L. 2003. Restaurants. In; B. Brother. (ED.). The international hospitality industry; structure, characteristics and issues. Butterworth-Heinemann. G.B.

Baraban, R. S., \& Durocher, J. F. 2010. Successful restaurant design. New Jersy: Wiley.

Blacharski, D. W. (2006). Superior customer service: how to keep customers racing back to your business-time-tasted examples from leading company. Atlantic Publishing Group, INC.USA. PP.42.

Boer, A.1992. The banking sector and small firm failure in the UK hotel and catering industry. International Journal of Contemporary Hospitality Management, 4(2).

Bogicevic, I. Fages E. \& Pier, A. 2008. Global branding: case study of McDonald's. Annee University. Paris. Accessed on: 13/ 07/ 2009. Available From: http://christophe.benavent.free.fr/IMG/pdf/AINI_2008_McDonald.pdf

Cebrzynski, G. 2008. Keep your eyes wide open; you never know where the competition will come from next. Nations Restaurants News. Lebhar-Friedman Inc.

Cox, R., Brittain, P., \& Cox, R. R. M. 2004. Retailing : an introduction. (5 ${ }^{\text {th }}$ ed.). Harlow. FT Prentice Hall.

Czinkota M. R. \& Ronkainen I. A. 2007. International Marketing. $8^{\text {th }}$ ed. Thomson southwestern. USA.

Ferrell, O.C. \& Hartline M. D. 2011. Marketing strategy. $4^{\text {th }}$ ed. Thomason South-Western. USA.

Franklin, B. 2005. Mc Journalism the local press and McDonaldization.Thesis. IN: S., Allan (ed). Journalism: Critical Issues. The Editators and Contributors. PP: 138. 
Gagliardi M. 2001.Models for Cultural Fit in Branding. Design Management Review, Boston. Accessed on 09/10/2009: Available From: http://www.allevio.com/Transcribing\%20Codes_Models\%20for\%20cultural\%20fit\%20in\% 20branding.pdf

Gambone G. (nd). Factors affecting the growth of fast food companies. Accessed on 23/01/2010 available from: http://www.ehow.com/about_5375595_factors-growth-fast-foodcompanies.html.

Gordon-Davis, L. \& Densburg L. V. 2004. The hospitality industry handbook on nutrition and menu planning for south African students and practitioners. Juta and Company Ltd. South Africa.

Gregory J.R. \& Wiechmann J.G. 2002. Branding across borders: a guide to global brand marketing.USA. Mc-Grow-Hill.

Gregory J.R. \& Wiechmann J.G. 2002. Branding across borders: a guide to global brand marketing.USA. Mc-Grow-Hill.

Gregory S.R., Smith K. D.\& Bickle M. C. 1998. Factors Contributing to Internal Customer Satisfaction and Commitment in Quick Service Restaurants. Journal of Restaurant \& Foodservice Marketing. 2 (4) 21-47.

Hahm R., \& Khan .M. A. 2001. Changing food consumption patterns and their impact on the quick service restaurant industry. Journal of Restaurant \& Foodservice Marketing, 4(3): 6579.

Hollensen, S. 2007. Global marketing : a decision-oriented approach. ( $4^{\text {th }}$ ed.). Harlow. Financial Times Prentice Hall.

Hollensen, S. 2007. Global marketing : a decision-oriented approach. $\left(4^{\text {th }}\right.$ ed.). Harlow. Financial Times Prentice Hall.

Hulghlett, M. 2009. Burger King ads attack McDonald's burger size. Accessed on 01/12/2009 available from: http://articles.chicagotribune.com/2009-08-

23/business/0908220020_1_burger-king-cheeseburger-big-mac

Jones, P. 2002. Introduction to hospitality operations: An indispensable guide to the industry. Cengage Learning.

Kara, A., Kaynak, E., \& Kucukemiroglu, O. 1995. Marketing strategies for fast-food restaurants: a customer view. International Journal of Contemporary Hospitality Management, 7(4): 1622.

Kim W G \& Kim H. 2004. Measuring Customer Based Restaurant Brand Equity. Cornell Hotel and Restaurants Administration Quarterly. Vol. 45. No. 2. Cornell University PP. 116.

Kim, W. C., \& Mauborgne, R. E. 2005. Blue ocean strategy : how to create uncontested market space and make the competition irrelevant. Boston, Mass. Harvard Business School.

Klessig, V. (2009). Giving 'fast food' a new name. The Daily Cardinal. Accessed on 5122008. Available from: http://www.dailycardinal.com/features/giving-fast-food-a-new-name1.993994.

Kovacik, C. 1998. Eating Out in south carolina's cities: the last fifty years. In B. G. Shortridge, \& J. R. Shortridge (Eds.), The taste of American place: a reader on regional and ethnic foods: Rowman \& Littlefield Pub Inc.

Kumar, S., \& Goel, B. 2007. Glocalization in food and agribusiness: strategies of adaptation to local needs and demands. Retrieved January, 12: 2009.

Lasserre, P. 2007. Global strategic management ( $2^{\text {nd }}$ ed.). Basingstoke: Palgrave Macmillan. 
McGinnis, J. M., Gootman, J. A., \& Kraak, V. I. 2006. Food marketing to children and youth: threat or opportunity?. Natl Academy Pr.

Molz, J., G. 2006. Sizing up the world: scale and belonging in narratives of round-the-world travel. In: P.M. Burns \& M. Novelli (eds.). Tourism and Social Identities: Global Frameworks and Local Realities. Elsevier. L.T.D. PP: 51.

Morgan, L. 2011. Factors that affect supply \& demand. Accessed on: 11/09/ 2011. Available from: http://www.ehow.com/info_8132502 factors-affect-supply-demand.html

Norlander, J. 1999. The geography of international hospitality development. In L. Yu (Ed.), The international hospitality business: Management and operations Haworth Press: Routledge.

Ottenbacher, M. C., \& Harrington, R. J. 2009. The product innovation process of quick-service restaurant chains. International Journal of Contemporary Hospitality Management, 21(5): 523-541.

Pizam, A. 2010. International encyclopedia of hospitality management: (2 ${ }^{\text {nd }}$ ed.). ButterworthHeinemann. Oxford.

Prakash, A., \& Singh, V. 2011. Glocalization in food business: strategies of adaptation to local needs and demands. Asian Journal of Technology \& Management Research Vol, 1(01).

Reid, R. D., \& Bojanic, D. C. 2010. Hospitality marketing management. New Jersy. Canada: Wiley.

Reiter, E. 1996. Making fast food: From the frying pan into the fryer: McGill Queens Univ Pr.

Sandhusen, R. 2008. Marketing ( $4^{\text {th }}$ ed.). Hauppauge, N.Y.: Barron's Educational Series.

Sriwongrat, C. 2008. Consumers' choice factors of an upscale ethnic restaurant. Master Thesis.

Sun, J., \& Chen, X. When Local Meets Global: Residential Differentiation, Global Connections, and Consumption in Shanghai.

Verdecho M. J., Alfaro J.J. \& Rodriguez-Rodriguez R. 2009. Supplier selection for collaborative new product development process: an application to the automotive industry. Proceedings of the International Symposium on the Analytic Hierarchy Process. The Polytechnic University of Valencia. 1-11

Vignali, C. 2001. McDonald's:"think global, act local"-the marketing mix. British Food Journal, 103(2): 97-111.

Walker, J. R. 2008. The restaurant: from concept to operation. New Jersy. Canada: Wiley.

Wright, L. T., Nancarrow, C., \& Kwok, P. M. H. 2001. Food taste preferences and cultural influences on consumption. British Food Journal, 103(5): 348-357. 